\title{
Lead Site aVF-Ventral
}

National Cancer Institute

\section{Source}

National Cancer Institute. Lead Site aVF-Ventral. NCI Thesaurus. Code C135387.

An aug mented unipolar electrocardiog ram limb lead in which the positive electrode is

situated at the hindquarters proximal to the sacrum and the negative electrode is a

combination of the electrode behind the right ear near the right mastoid process and the electrode near the apex of the heart (located in the ICS of left 5-6 rib close to the sternum). (CDISC) 